\title{
Clinical Aspects of Acute Rheumatic Fever in Pernambuco, Brazil
}

\author{
Lurildo R. Saraiva ${ }^{1 *}$, Cleusa Santos Lapa ${ }^{2}$, Thiago Barros Saraiva Leão ${ }^{3}$ \\ 'Federal University of Pernambuco, Recife, Brazil \\ ${ }^{2}$ The Maternal and Child Institute of Pernambuco (IMIP), Recife, Brazil \\ ${ }^{3}$ Federal University of Pernambuco, Recife, Brazil
}

\section{Article Info}

\section{Article Notes}

Received: December 24, 2018

Accepted: February 4, 2019

\section{${ }^{*}$ Correspondence:}

Lurildo R. Saraiva, MD, Estrada do Arraial, 2405, Apt. 704CEP. 52051-380, Tamarineira, Recife, Pernambuco, Brasil; Email: lurildocleano@hotmail.com

${ }^{\circ} 2019$ Saraiva LR. This article is distributed under the terms of the Creative Commons Attribution 4.0 International License.

\section{Key words:}

Rheumatic fever

Rheumatic carditis

Valvopathies

QTc interval

QTc prolongation

\section{Abstract}

Rheumatic fever and subsequent rheumatic heart disease remain high in areas with high levels of poverty as in our country as in Pernambuco State, northeast of the Brasil. Clinical aspects peculiar to the disease, once easily found in rich countries, are still present in our infirmaries, including curious alterations in the electrocardiogram. Elongated QTc and cardiac arrhythmias can be recorded in about $30 \%$ of acute cases, with the possibility of sudden death. Cardiac surgery imposes itself for the cure of heart failure rebel against newly introduced drugs in medical practice.

\section{Introduction}

When in 1949, DÉCOURT ${ }^{1}$ demonstrated in a significant number of patients that the QTc interval in acute rheumatic fever (ARF) tended to be prolonged, when compared to values obtained in a normal population, with significant difference between the two groups, it was not imagined that this discovery anticipated the great valorization of that electrocardiographic index, which, if prolonged, could be indicative of sudden death (SD) ${ }^{2,3}$.

Although a possible "QTc prolongation theory" is not well accepted by all, the observation by LIBERMAN et. al ${ }^{4}$ showed in a case of SD due to acute rheumatic carditis, the QTc elongation precedence and the occurrence of Torsades des pointes. It is not known whether severe cardiac arrhythmias have occurred in descriptions of rheumatic myocarditis as a producer of $\mathrm{SD}^{5}$, and in others, the clinical presentation is unspecific and the neurological symptoms prominent ${ }^{6}$.

Subsequent studies amongst us have shown that the dispersion of this interval (dQT) in ARF is increased in both clinically carditis ${ }^{7}$ and subclinical rheumatic carditis (SCC) ${ }^{8}$, correlating with the presence of valvar involvement in the disease.

In Pernambuco, in the Northeast of the Brazil, ARF remains with high incidence, due to social inequalities ${ }^{8}$ that suffers the majority of the poor population, in the ninth most unequal society in the world. Maybe for this reason, the disease presents itself, even today, with unusual aspects in relation to richer regions 9 .

\section{Disease Presentation in Children and Adolescents in Rheumatic Activity}

The diagnosis of ARF is made according to the 2015 Modified Jones Criteria, specifically those addressed to poor areas of the world 
10. Thus, in addition to the importance of classical signs, some others are particularly relevant amongst us such as isolated monoarthritis, polyarthritis, polyarthralgia or monoarthralgia, clinical and /or SCC, a not very high fever (around $38^{\circ} \mathrm{C}$ ), and the erythrocyte sedimentation rate of $30 \mathrm{~mm}$ (Table 1). It is important to note that the most recent change in the Jones Criteria was based primarily on echocardiographic findings from poorer countries with the frequent finding of silent valve lesions, witch similarly modified the echocardiographic findings recorded in more rich regions ${ }^{11}$

Considered to be the second leading cause of cardiac surgery in the Brazil, there probable is an underestimated incidence of the disease since patients who do not require

Table 1. JONES Criteria for Medium and High Populations Risk of Developing ARF (Pernambuco, 2019)

\begin{tabular}{l} 
Patients with Previous Evidence of Streptococia (elevated ASLO) \\
1. Major Criteria \\
Clinical or Subclicinal carditis \\
Arthritis: Monoartritis or Polyarthritis and Polyartralgia \\
Sydenham ' Chorea \\
Eythema Marginatum \\
Subcutaneous nodules \\
$\quad$ 2. Minor Criteria \\
Monoartralgia \\
Fever (> $38^{\circ} \mathrm{C}$ ) \\
Erythrocyte sedimentation rate (ESR) $\geq 30 \mathrm{~mm} / \mathrm{h}$ \\
C-Reactive protein (CRP) $\geq 3.0 \mathrm{mg} / \mathrm{dL}$ \\
PR interval prolongation, according to age \\
3. Rare Condtions \\
Rheumatic pneumonia \\
\hline
\end{tabular}
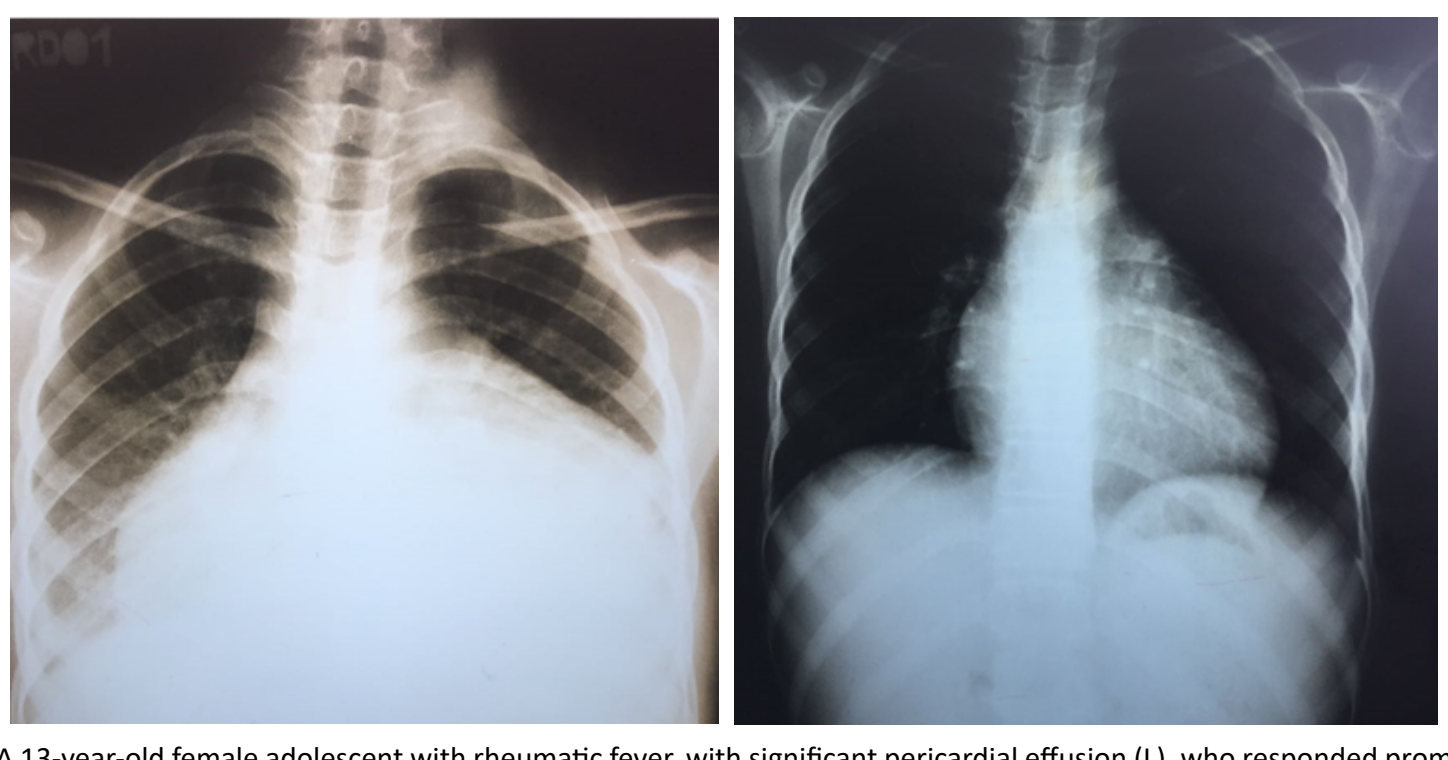

Figure 1: A 13-year-old female adolescent with rheumatic fever, with significant pericardial effusion (L), who responded promptly to the use of prednisone in the course of ten days (R) (IMIP, 2017) hospital admission, who once not taking appropriate secondary prophylaxis, end up developing surgical valvar diseases in the third or fourth decades of life, or even sooner ${ }^{12}$.

Hospital admission is almost always reserved for children with severe carditis in the first decade of life, who present in pediatric emergency units with congestive heart failure (CHF), sometimes, resulting in acute pulmonary edema or massive pericardial effusion (PE). Figure 1 shows the chest X-ray of a 13-year-old girl, from a very poor family from the countryside region of Pernambuco, where the PE overlaps, in clinical practice, with the associated mitroaortic valvopathy; after ten days of corticosteroid therapy, there was a notable reduction in cardiac volume (Fig. 1)

In hospitalized children for rheumatic activity, it is not uncommon to find disseminated subcutaneous nodules, inserted in the dorsal region of the hands or feet, in the clavicular region, on tendons or on the scalp, mainly in the occipital region of the skull; curiously, Dr. Cleusa Lapa and I have recently seen subcutaneous nodules along the spine of an eight-year-old boy from the crountryside (northeastern ' backwoods "Sertão") of Pernambuco, admitted to the IMIP, similar to those seen by CHEADLE ${ }^{13,14}$ in London in 1889, as one of his acute patients with signs of malnutrition, which allows us to conclude that, after more than 100 years, the ARF, in areas of the Brazil, presents with stigmas similar to those of 19th century England, in patients from regions with striking signs of poverty (Fig. 2)

Another controversial aspect accepted by DÉCOURT ${ }^{1}$ is the so-called "rheumatic pneumonia", almost always located in the lower third of the right lung, in a justcardiac position. Usually, there is a clinical-radiological disproportion, in the sense of little clinical symptomatology 


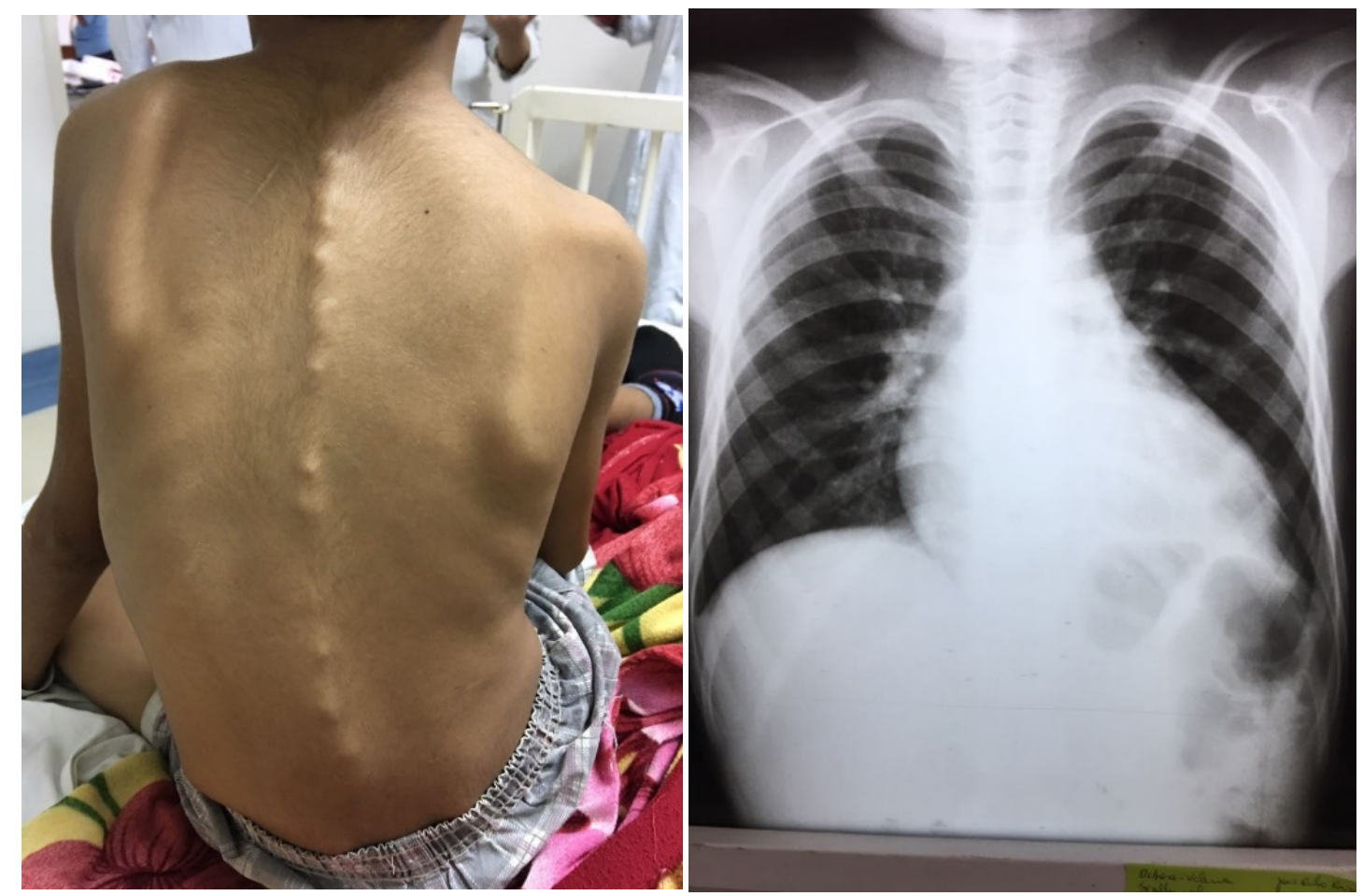

Figure 2: Eight-year-old boy, son of peasants, in the first rheumatic outbreak. Notice the richness of subcutaneous nodules on the spine. On the right, chest radiography shows cardiomegaly, with the volumetric increase of the left heart chambers (IMIP, 2016)

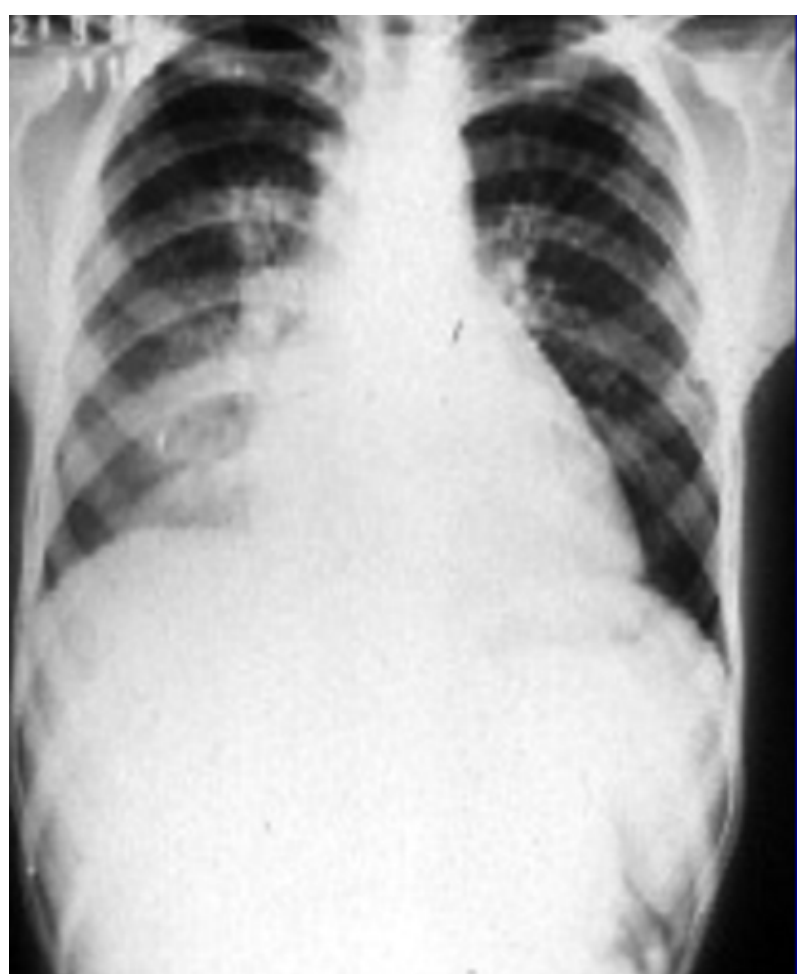

Figure 3: A 14-year-old boy from the interior of Pernambuco, during the second rheumatic outbreak, with moderate mitral regurgitation, shows a radiological image compatible with rheumatic pneumonia in the lower third of the right lung (UFPE, 1998)
- dry cough, pleuritic pain, rarely bloody sputum, - and the expressive radiological alterations. For some authors, the image would be due to venocapillary congestion, but always in conjunction with relevant rheumatic carditis, with the patient suffering from severe CHF; well before, in the United Kingdom, it was described by CHEADLE ${ }^{14}$, even in epidemic presentation. Usually improves with corticosteroid therapy used for the concurrent carditis.

The ECG shows cardiac left and or right chambers enlargement, when signs of secondary pulmonary arterial hypertension are present.

In Fig. 4 we observed an increase of this ECG parameter in a second rheumatic outbreak of a patient with migratory arthritis of large joints and severe carditis, associated with mitral and aortic valve insufficiency. In 1949, DÉCOURT ${ }^{15}$, in your Thesis of Professorship, drew attention to the peculiar ascending aspect of the ST segment in the circumstance, fact little valued.

Different forms of AV block may occur in the same patient, ranging from the first to the third degree $A V$ block, in a short time, constituting what we call "clinicalelectrocardiographic disproportion " in ARF, as in this case of a boy with atypical symptoms (nausea and dizziness), ASLO 748 Todd units, and with SCC and mild mitral and aortic insufficiency, detected on the echocardiogram (CAVALCANTI, C., Recife, 2014). 

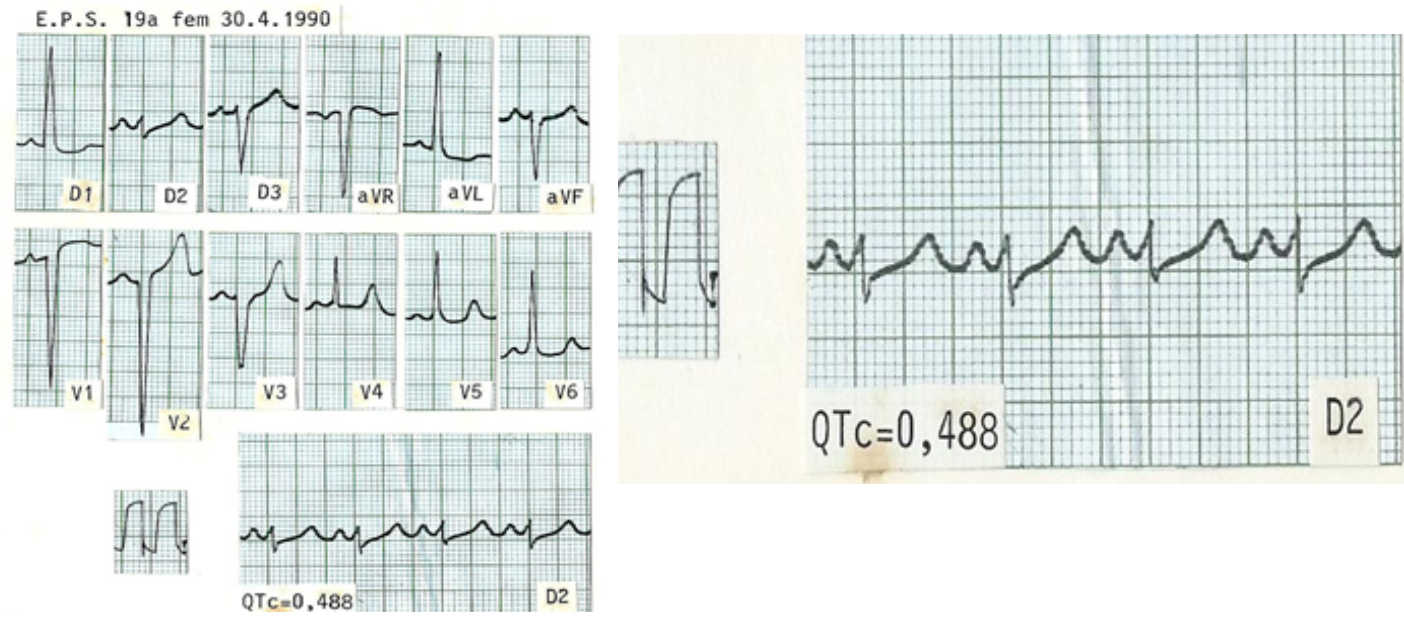

Figure 4: ECG of adolescent in rheumatic outbreak reveals regular sinus rhythm, with orientation of the ÂQRS at - 30ㅇ by left ventricular systolic overload. Note the QTc prolongation, with ST segment in a peculiar way, confusing with the ascending branch of the T wave (UFPE, 1990)
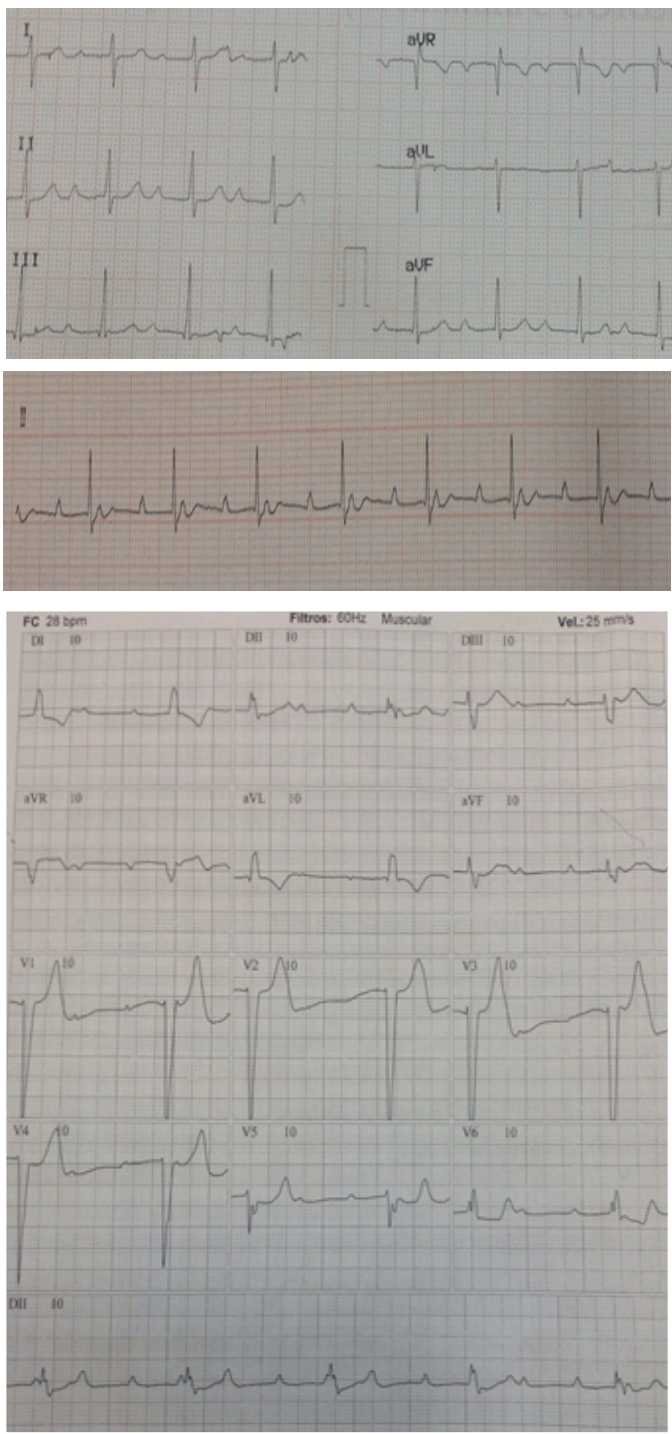

1st day: first degree AV block

2nd day: second degree MOBITZ 2:1

\section{3rd day: total AV block, also observing the rare complete left bundle branch block16}

Figure 5: Varied forms of atrioventricular block in acute rheumatic subclinical carditis in a 14-year-old adolescent 
At no time, with the patient at rest, the electrical phenomenon was accompanied by symptomatology indicative of low cardiac output. It was treated with prednisone at the dose of $2 \mathrm{mg} / \mathrm{kg} /$ day and intramuscular use of penicillin benzathine 1,200,000 U every 15 days.

\section{ARF Clinical and Laboratory Markers in Pernambuco}

ARF occurs in about $3 \%$ of patients with oropharyngeal or Waldeyerian ring infection, including otitis caused by Lancefield Group A group A Streptococcus. The possibility that it may occur from pyoderma, accepted by Australian authors ${ }^{17}$, is not yet an accepted fact amongst us.

Why does this percentage of $3 \%$ remain the same in all parts of the world where ARF is described? Even today, despite the great advance in the understanding of the pathogenesis of the disease, it is not well known the reason, but CHEADLE himself described, at the end of the 19th century, the occurrence of the disease in London families, his own included, with his wife and only son being rheumatic ${ }^{14,18}$

The search for an explanation led, in the first half of the twentieth century, to a series of scientific works, especially those produced at the Good Samaritan Hospital, in Boston, USA $^{19}$. Despite McCarty's 1946 statement that "in some way, the Streptococcus is located in the intimacy of the heart of the rheumatic patient", German authors simultaneously found autoantibodies in the blood of patients with rheumatism, that turned against cardiac tissue ${ }^{20}$.

With the current knowledge, we can affirm that the patient with ARF is recognized by three basic characteristics:

1) It presents peculiar immunity to the presence of oropharyngeal infection by strains of Lancefield Group A Streptococcus, and in our country, it is recognized by the HLA-DR system, through the locus HLA-DR7, according to GUILHERME et. $a l^{21}$;

2) It presents frequent electrical alteration, with a tendency to lengthen the QTc interval in the ECG, in the face of persistent inflammation, recently discussed by LAZZERINI et. $a l^{22}$;

3) After developing ARF, especially Chorea, it may have a psychic behavior distinct of the obsessivecompulsive nature, as shown by the works of SWEDO et. $a l^{23}$ and by HOUNIE et. $a l^{24}$.

The life of the American artist ANDY WARHOL, who has had Chorea as a teenager, is exemplary, as is possible the life of the Austrian genius of classical music, WOLFGANG MOZART, facts of general knowledge.

(Table 1) outlines the relevant clinical findings among us, according to the JONES Criteria, modified in $2015^{25}$.

\section{ARF'S Treatment and Prevention in Pernambuco}

The immune picture with peculiar characteristics in the genesis of the disease includes an "acute initial phase", with the production of antibodies after stimulation of B lymphocytes, through the antigen presenting cells (macrophages), containing streptococcal epitopes. These autoantibodies will lead to cutaneous lesions (Erythema marginatum), subcutaneous nodules, arthritis of large joints and Sydenham's chorea.

Simultaneous, $\mathrm{T}$ lymphocyte stimulation leads to a "later phase" involving cardiac valves, especially mitral and aortic ones, with regurgitation, - this process tends to be persistent, as if there was a permanent "presence of the causative bacterium in the human organism", resulting in ARF as being a "disease without cure" 25 . We can now understand the old McCARTY statement.

Echocardiographic study in cases without audible murmurs allows the recognition of $\mathrm{SCC}^{26,27}$, which shows signs similar to those observed in clinical carditis, such as Meynert's nodules and Erythema marginatum. The same Doppler echocardiographic technique, which provided enormous support for surgical decisions in diseased valves ${ }^{28}$ has allowed identify a much higher prevalence in Mozambique and in other African countries than it was previously accepted - in the Mozambican case, the estimate has risen up to $30 \%{ }^{29}$.

Considering the immune status involved in the genesis of $\mathrm{RF}$, the treatment performed in Pernambuco is based on the use of corticosteroids - prednisone at a dose of 1 to 2 $\mathrm{mg} / \mathrm{kg} /$ day as an attack and gradual reduction, 10 to $20 \%$ per week - allowing to cover the whole rheumatic cycle, which takes about 90 days ${ }^{1}$.

Acetal-salicylic acid (ASA) is used solely in the predominantly articular forms, at a dose of 50 to 70 or $100 \mathrm{mg} / \mathrm{kg} / \mathrm{day}$, with a gradual decrease from the 10th day. The drug response of severe pain and signs of joint inflammation is extraordinary after 24 to 48 hours, so that if there is no improvement within that time, the rheumatic etiology should be questioned. Despite the recognized efficacy of this drug, which is also inexpensive, other antiinflammatories may be useful. ${ }^{25}$

In Chorea, including behavior conduct disorders, haloperidol is used at a dose of $1 \mathrm{mg} /$ day, which can be carefully increased until involuntary movements disappear; if there is simultaneous rheumatic carditis we can opt for prednisone isolated or associated with haloperidol. Another useful drug in the control of rheumatic chorea is valproic acid ${ }^{30}$.

In any of the described situations, as a preventive measure, benzathine penicillin should be used at a dose of $1,200,000 \mathrm{U}$ intramuscularly every 21 days, in patients 
weighing more than $20 \mathrm{~kg}$; below that weight, the recommended dose is $600,000 \mathrm{U}$ intramuscularly

Treatment of congestive heart failure (CHF) is based on a low sodium diet, use of diuretics and vasodilators, including carvedilol and angiotensin II converting enzyme inhibitors. Not infrequently, only urgent surgical management can be used to treat rheumatic outbreak associated with severe valvar disease $\mathrm{e}^{28,31}$.

The "Brazilian Guidelines for the Treatment and Prevention of Rheumatic Fever" are located at the Brazilian Societies of Cardiology and Pediatrics websites, which covers all clinical possibilities.

\section{Conclusion}

In developed countries, after the 1960s, the epidemiological picture of ARF has changed, with substantial improvement, to the point where prevalence ranged from 250 cases to 100,000 people in the State of Minnesota, USA, in the early 20th century, to about less than one case for a hundred thousand these days. This was due to the social and economic improvement of the excluded people, and perhaps the type predominant rheumatogenic streptococcal strain.

In our country, even with the decrease of new cases, we continue to identify extremely serious patients from vulnerable regions, due to the orthodox application of neoliberal economic measures, with dire results upon the poor.

The words of the great pathologist Rudolf VIRCHOW ${ }^{32}$, in 1849 , remain in the present:

“THE SOCIAL BASIS OF THE DISEASE - POVERTY, IGNORANCE, OPPRESSION - NEEDED A POLITICAL REMEDY JUST AS THE BIOLOGICAL FACTORS NEEDED A STRICTLY BIOMEDICAL ONE"

\section{References}

1. Décourt lv. A sístole elétrica ventricular: métodos de apreciação, valores normais e desvios em estados patológicos. Tese de Cátedra. São Paulo: Faculdade de Medicina. Universidade de São Paulo. 1949; 178.

2. Jervell A, Lange-nielsen F. Congenital deaf-mutism, functional heart disease with prolongation of the QT interval. and sudden death. Am Heart J. 1957; 54: 59-68.

3. Lokhandwala Y, Panicker GK, Deshpande S. Sudden cardiac death - an Indian perspective. CVD Prev Ver Control. 2009; 4: 103 - 6.

4. Liberman L, Hordof AJ, Alfayyadh M, et al. Torsade de pointes in a child with acute rheumatic fever. J pediatr. 2001; 138: 280 - 2.

5. Osculati A, Visonà SD, Ventura F, et al unexpected death of a 15-year-old boy due to pancarditis. A case report and possible etiopathogenesis. Medicine. 2016; 95 (35): 1 - 3.

6. Rérolle C, Faisant M, Lefrancq T, et al. Sudden death due to undiagnosed Rheumatic Heart Disease in a child. J forensic sci. 2016; 61: 848 - 50.

7. Remigio de Aguiar MI, Saraiva LC, Santos CL. QT dispersion predicting acute rheumatic carditis. Cardiol Young. 2010; 20(5): $473-6$.
8. Leão TBS. Estudo da dispersão do intervalo QTc em crianças portadoras de cardite reumática sub-clínica. Tese para obtenção do Título de Mestre em Medicina Interna. Universidade Federal de Pernambuco. 2007; 78.

9. Brown A, Mcdonald MI, Calma T. Rheumatic fever and social justice. MJA. 2007; 186 (11): 557 - 8.

10. Taranta A, Narula J, Virmani R, et al. A history of rheumatic fever (and of its idea). In: eds. Rheumatic Fever. Washington: American Registry of Pathology. 1999; 1-40.

11. Gewitz MH, Baltimore RS, Tani LY, et al. Revision of Jones Criteria for the diagnosis of Acute Rheumatic Fever in the Era of Doppler Echocardiography. A Scientific Statement from the American Heart Association. Circulation. 2015; 131: 1806 - 18.

12. Gewitz MH, Baltimore RS, Tani LY, et al. Rheumatic Fever in the era of Doppler Echocardiography. A scientific Statement from the American Heart Association. Circulation. 2015; 131: 1806- 18.

13. Saraiva LR, Santos CL, Ventura C, et al. On the gravity of the acute rheumatic fever in children from Pernambuco, Brasil. Arq Bras Cardiol. 2013; 101 (3): e64-e68.

14. Cheadle WB. The various manifestations of the rheumatic state as exemplified in childhood and yearly life. Lancet. 1889; 1: 821-7.

15. Décourt LV. Doença Reumática. 2 ed. São Paulo: Sarvier. 1972.

16. Yahalom M, Jerushalmi J, Roguin N. Adult case rheumatic fever: a rare case presenting with left bundle branch block. PACE. 1990; 13: 123-7.

17. Mcdonald M, Currie BJ, Carapetis JR. Acute rheumatic fever: A chink in the chain that links the heart to the throat. Lancet Infect Dis. 2004; 4: $40-5$.

18. Dougherty S, Khorsandi M, Herbstz P. Rheumatic heart disease screening: current concepts and chalenges. Ann Pediatr Card. 2017; 10: 39-49.

19. Lancefield RC. Current knowledge of type-specific M antigens of Group A streptococci. J Immulol. 1962; 89: 307.

20. Mccarty M. An adventure in the pathogenetic maze of Rheumatic Fever. J Infect Dis. 1981; 143: 375 - 85.

21. Guilherme L. Bases celulares e moleculares do processo auto-imune na Doença Reumática. Tese de Doutoramento. Universidade de São Paulo. 1992; 111.

22. Lazzerini PE, Capecchi PL, Laghi-pasini F. Long QT syndrome: an emerging role for Inflammation and Immunity. Front Cardiovasc Med. 2015; 2: 1-17.

23. Swedo SE, Rapoport JL, Cheslow DL, et al. High prevalence of Obsessive-Compulsive symptoms in patients with Sydenham's chorea. Am J Psychiatry. 1989; 146: 246 - 249.

24. Hounie AG, Pauls DL, Mercadante MT, et al. Obsessive compulsive spectrum disorders in Rheumatic Fever with and without Sydenham `s Chorea. J Clin Psychiatry. 2004; 65(7): 994-9.

25. Carapetis JR, Beaton A, Cunningham MW, et al. Acute rheumatic fever and rheumatic heart disease. Nature Rev Dis Primers. 2016; 2: 15084.

26. Zuhlke LJ, Beaton A, Engel ME, et al. Group A Streptococcus, Acute Rheumatic Fever and Rheumatic Heart Disease: Epidemiology and Clinical Considerations. Curr Treat Options Cardio Med. 2017; 19(15): 1- 23.

27. Tubridy-clark M, Carapetis JR. Subclinical carditis in Rheumatic Fever: A systematic review. Int J Cardiol. 2007; 119 (1): 54 - 58.

28. Lancellotti P, Rosenhek R, Pibarot P, et al. ESC Working Group on Valvular Heart Disease Position Paper Heart Valve Clinics: organization, structure, and Experiences. Eur Heart J. 2013; 34 : 1597 - 1606. 
29. Marijon E, Phala O, Celermajer DS, et al. Prevalence of Rheumatic Heart Disease detected by Echocardiographic Screening. Nejm. 2007; 357: $470-6$

30. Fusco C, Spagnoli C. Corticosteroid treatment in Sydenham`s chorea Eur J Paediatr Neurol. 2018; 22: 327 - 331.
31. Yacoub MH. In searching of Living Valve Substitutes (Editorial) JACC. 2015; 66 (8): 889 - 91.

32. Mcneely IF. "MEDICINE on a GRAND SCALE": RUDOLF VIRCHOW, Liberalism, and the Public Health. University college of london occasional publication no 1. the trustee of the welcome trust, london. 2002; 94. 